\title{
On the Stress Corrosion Cracking and Hydrogen Embrittlement Behavior of Austenitic Stainless Steels in Boiling Saturated Magnesium Chloride Solutions
}

\author{
Osama M. Alyousif ${ }^{1}$ and Rokuro Nishimura ${ }^{2}$ \\ ${ }^{1}$ Department of Mechanical Engineering, Kuwait University, P.O. Box 5969, Safat 13060, Kuwait \\ ${ }^{2}$ Department of Applied Materials Science, Osaka Prefecture University, 1-1, Gakuen-cho, Sakai, Osaka 599-8531, Japan
}

Correspondence should be addressed to Osama M. Alyousif, osama.alyousif@ku.edu.kw

Received 5 January 2011; Accepted 14 September 2011

Academic Editor: W. Ke

Copyright (C) 2012 O. M. Alyousif and R. Nishimura. This is an open access article distributed under the Creative Commons Attribution License, which permits unrestricted use, distribution, and reproduction in any medium, provided the original work is properly cited.

\begin{abstract}
The stress corrosion cracking (SCC) and hydrogen embrittlement (HE) behaviors for types 304, 310, and 316 austenitic stainless steels were investigated in boiling saturated magnesium chloride solutions using a constant load method under different conditions including test temperature, applied stress, and sensitization. Both of type 304 and type 316 stainless steels showed quite similar behavior characteristics, whereas type 310 stainless steel showed a different behavior. The time to failure $\left(t_{f}\right)$ parameter was used among other parameters to characterize the materials behavior in the test solution and to develop a mathematical model for predicting the time to failure in the chloride solution. The combination of corrosion curve parameters and fracture surface micrographs gave some explanation for the cracking modes as well as an indication for the cracking mechanisms. On the basis of the results obtained, it was estimated that intergranular cracking was resulted from hydrogen embrittlement due to strain-induced formation of martensite along the grain boundaries, while transgranular cracking took place by propagating cracks nucleated at slip steps by dissolution.
\end{abstract}

\section{Introduction}

The stress corrosion cracking behavior of austenitic stainless steels in chloride and other corrosive solutions has been extensively investigated using various methods [1-7]. The constant load method can produce a corrosion elongation curve which can be used to obtain three useful parameters namely, time to failure $\left(t_{f}\right)$, steady-state elongation rate $\left(l_{\mathrm{ss}}\right)$, and transition time to time to failure ratio $\left(t_{\mathrm{ss}} / t_{f}\right)$. These parameters are useful in analyzing the failure behavior. In particular, the steady-state elongation rate $\left(l_{\mathrm{ss}}\right)$ can be used to predict the time to failure $\left(t_{f}\right)[3,8]$. Recent studies found that the characteristics of the steady-state elongation rate can be applied to SCC of type 430 ferritic stainless steels in acidic chloride and sulfate solutions by using the constant load method [9].

In previous papers $[10,11]$, we have reported that solution-annealed austenitic stainless steels show two different cracking modes depending on the cracking mechanism; transgranular (TG) for SCC and intergranular (IG) for HE depending on the test temperature which was critical in controlling the cracking mode. In other papers [12, 13], we have also reported that sensitized stainless steels have a lower susceptibility for SCC and HE than that for solution-annealed austenitic stainless steels. On the basis of these findings, a new aspect for intergranular hydrogen embrittlement mechanism for solution-annealed types 304, 316 and 310 austenitic stainless steels was proposed [14]. The objectives of this paper are to elucidate the effects of test temperature, applied stress and sensitization on SCC (or HE) susceptibility of austenitic stainless steels, and to discuss a proposed cracking mechanism for austenitic stainless steels in chloride solutions.

\section{Experimental}

The specimens used were commercial type 304, 316, and 310 austenitic stainless steels whose chemical compositions 


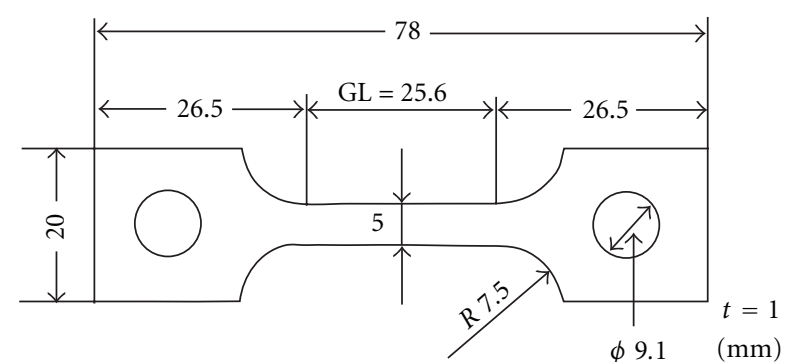

Figure 1: Geometry of specimens (dimensions in $\mathrm{mm}$ ).

(wt\%) are shown in Table 1. As shown in Figure 1, the geometry for stress corrosion cracking experiments is as follows: the gauge length is $25.6 \mathrm{~mm}$, the width $5 \mathrm{~mm}$, and the thickness $1 \mathrm{~mm}$. The specimens were solution-annealed at $1373 \mathrm{~K}$ for $3.6 \mathrm{ks}$ under an argon atmosphere and then waterquenched. Another batch of specimens of the same materials was subjected to a sensitization heat treatment at $923 \mathrm{~K}$ under an argon atmosphere for 24 hours then water quenched. Prior to experiments, the solution-annealed specimens were polished to 1000 grit emery paper, degreased with acetone in an ultrasonic cleaner and washed with distilled water. After the pretreatment, the specimens were immediately set into a stress corrosion cracking cell. Stress corrosion cracking tests were conducted in boiling saturated magnesium chloride solutions, whose boiling temperatures were changed by the change in the concentration of magnesium chloride. The test temperature range was between $403 \mathrm{~K}-428 \mathrm{~K}$. The applied stress was in the range from 0 to $500 \mathrm{MPa}$. Some tests were performed at a constant applied stress with varying test temperature to study the effect of test temperature, and some experiments were performed at a constant test temperature with varying applied stress to study the effect of applied stress. All experiments were carried out under an open circuit condition.

A lever-type constant load apparatus (lever ratio $1: 10$ ) to which three specimens can be separately and simultaneously attached was used with a cooling system on the top to avoid evaporation of the solution during the experiments. The specimens were insulated from rod and grip by surfaceoxidized zirconium tube. Elongation of the specimens under a constant load was measured by an inductive linear transducer with an accuracy of $\pm 0.01 \mathrm{~mm}$.

\section{Effect of Test Temperature}

The effects of test temperature were studied for austenitic stainless steels in boiling saturated magnesium chloride solutions and the details and results of this work are shown in a previous publication [10]. Figure 2 depicts the logarithm of the parameter $t_{f}$ versus the reciprocal of the test temperature for the three stainless steel types used in the experiments. For type 304, the relationship between $t_{f}$ and $1 / T$ falls in a straight line, shown as region-I, until a test temperature of about $413 \mathrm{~K}\left(1 / T=2.42 \times 10^{-3}\right)$, below which the relationship deviates from the linearity. The region from $413 \mathrm{~K}\left(1 / \mathrm{T}=2.42 \times 10^{-3}\right)$ to a threshold test temperature, approximately $403 \mathrm{~K}\left(1 / T=2.48 \times 10^{-3}\right)$, below which little fracture takes place within a laboratory time scale, was called region-II. For type 316 , the parameter $t_{f}$ was also grouped into two regions; region-I at test temperatures above $424 \mathrm{~K}\left(1 / \mathrm{T}=2.36 \times 10^{-3}\right)$ and region-II with test temperatures below $424 \mathrm{~K}\left(1 / T=2.36 \times 10^{-3}\right)$ up to a threshold test temperature of about $408 \mathrm{~K}(1 / T=2.45 \times$ $\left.10^{-3}\right)$. The $t_{f}$ values of type 310 showed slight sensitivity to test temperature. The $t_{f}$ values for type 310 were grouped in a straight line which constitutes region-I until a threshold test temperature of about $408 \mathrm{~K}\left(1 / T=2.45 \times 10^{-3}\right)$ without region-II. Therefore, in Figure 2, the elongation curve for type 310 at $416 \mathrm{~K}\left(1 / \mathrm{T}=2.40 \times 10^{-3}\right)$ falls in region-I, while that for type 316 at $416 \mathrm{~K}\left(1 / \mathrm{T}=2.40 \times 10^{-3}\right)$ falls in regionII.

Type 304 is a metastable austenite, and it is very susceptible to martensite formation [15]. This type of austenitic stainless steels was used extensively in investigating hydrogen embrittlement behavior because of its material composition, structure "instability", intergranular cracking mode, and ability to phase transform upon hydrogen charging or induced strain. The material displayed two different behaviors on the basis of the test temperature dependency. Hydrogen embrittlement behavior occurred at test temperatures below the critical temperature and SCC behavior occurred at test temperatures above the critical temperature, where the critical temperature is the temperature between region-I and region-II. It can be concluded based on the results of using the constant load method that type 304 is very susceptible to hydrogen embrittlement as well as stress corrosion cracking in the saturated boiling magnesium chloride solutions. This notion will be further discussed in the following section.

Type 316 has also a metastable austenite, and it is moderately susceptible to martensite formation. The material exhibited a dual cracking behavior similar to type 304 and this may be attributed to the closely identical chemical composition for both types. Type 316 had a higher critical temperature than type 304. This type of austenitic stainless steel can also be branded as susceptibility to both of hydrogen embrittlement and SCC failure depending on the test temperature in magnesium chloride solution as shown in the postfracture micrographs.

But when it comes to type 310 which has a stable austenite structure, the material did not exhibit any hydrogen embrittlement cracking features based on the postfracture analysis of the broken samples. This behavior can be explained by the material's high content of chromium which is a natural inhabitant of martensite transformation, and this may be the reason that this type of stainless steels is susceptible to SCC only in magnesium chloride solutions.

Hydrogen is a product of the electrochemical reactions at the metal surface. For metastable austenitic steels like types 304 and 316, the strain-induced martensite along the grain boundaries will enhance the hydrogen permeation [16-18]. Martensite structure has a very high diffusivity coefficient and very small hydrogen content compared to those of the austenite. This may explain the intergranular cracking as the crack preferential path is through the martensite structure 
TABLE 1: Chemical compositions (wt\%) and mechanical properties of the austenitic stainless steels used.

\begin{tabular}{lcccccccccc}
\hline & $\mathrm{C}$ & $\mathrm{Si}$ & $\mathrm{Mn}$ & $\mathrm{P}$ & $\mathrm{S}$ & $\mathrm{Ni}$ & $\mathrm{Cr}$ & $\begin{array}{c}\text { Mo } \\
\sigma_{\text {Yield }} \\
(\mathrm{MPa})\end{array}$ & $\begin{array}{c}\sigma_{\text {Tensile }} \\
(\mathrm{MPa})\end{array}$ \\
\hline SS304 & 0.06 & 0.35 & 0.96 & 0.027 & 0.004 & 8.13 & 18.20 & - & 276 \\
SS310 & 0.05 & 0.84 & 1.27 & 0.016 & 0.001 & 19.30 & 24.76 & - & 275 \\
SS316 & 0.06 & 0.70 & 0.96 & 0.031 & 0.004 & 10.15 & 16.98 & 2.22 & 323 & 636 \\
\hline
\end{tabular}

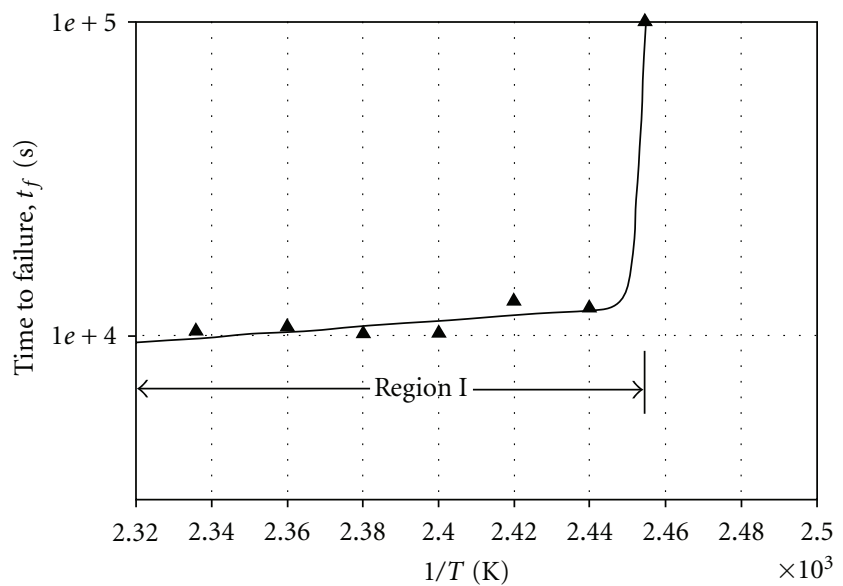

- SS 310

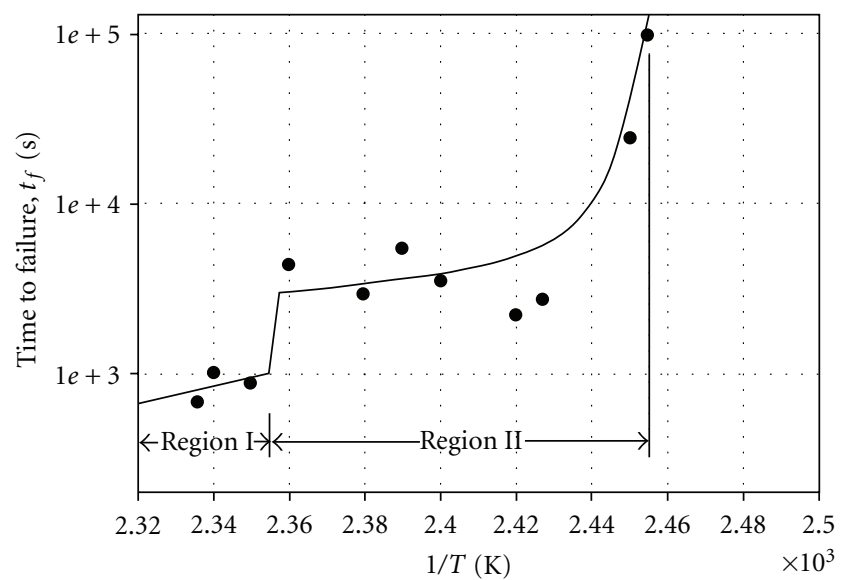

- SS 316

(a)

(b)

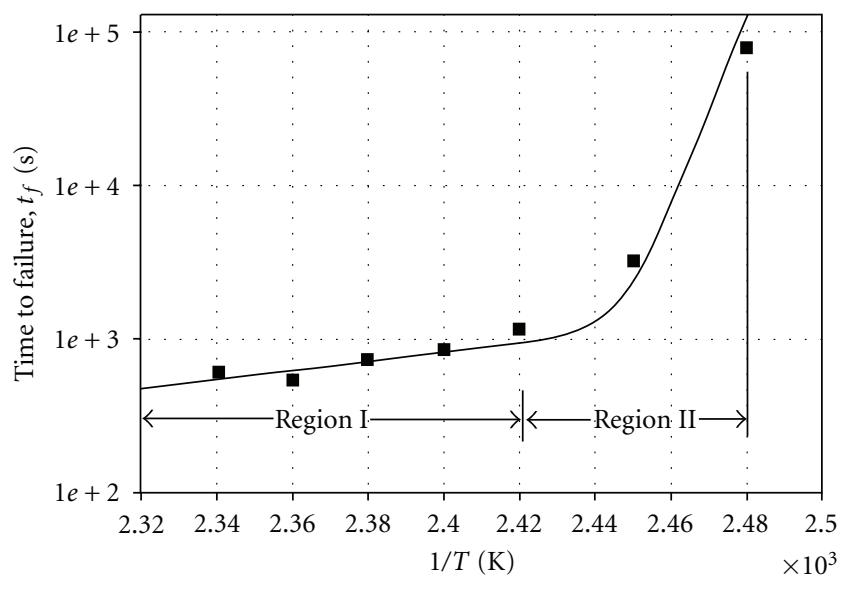

- SS 304

(c)

Figure 2: The relationship between reciprocal of test temperature $(1 / T)$ and logarithm of time to failure $\left(t_{f}\right)$ for type 310 , 304 , and 316 steels in boiling saturated $\mathrm{MgCl}_{2}$ solutions.

facilitated by the higher diffusion rates of hydrogen. At high temperatures, the corrosion rate will be higher than the corrosion rate at low temperature and this will result in a predominant metal dissolution at the crack tip faster than the hydrogen entry to the structure, and this will enhance the predominance of SCC mechanism. The lower temperature means lower corrosion reaction rates, and this will prohibit the film rupture mechanism hence letting the hydrogen embrittlement to take place and thus controlling the cracking mechanism. It is worth noting that increasing the amount of $\alpha^{\prime}$-martensite content in the structure produced by applied stress (or strain) will increase the susceptibility of the material to hydrogen embrittlement [18]. Type 310 is a stable austenitic stainless steel, and no evidence 


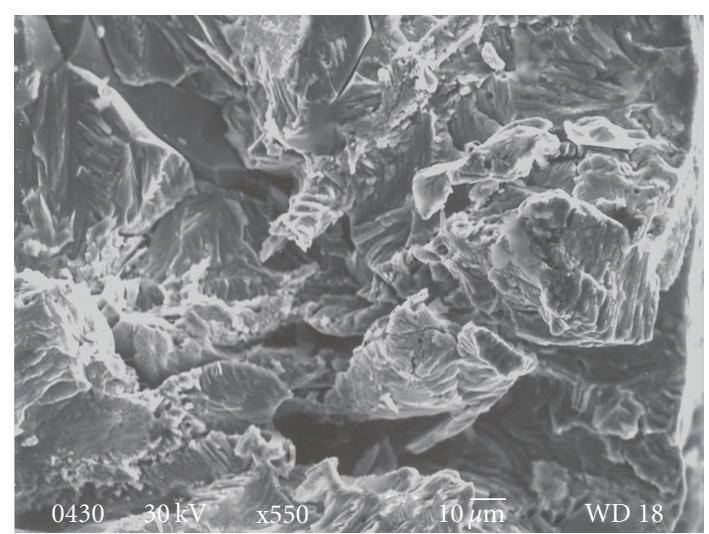

(a)

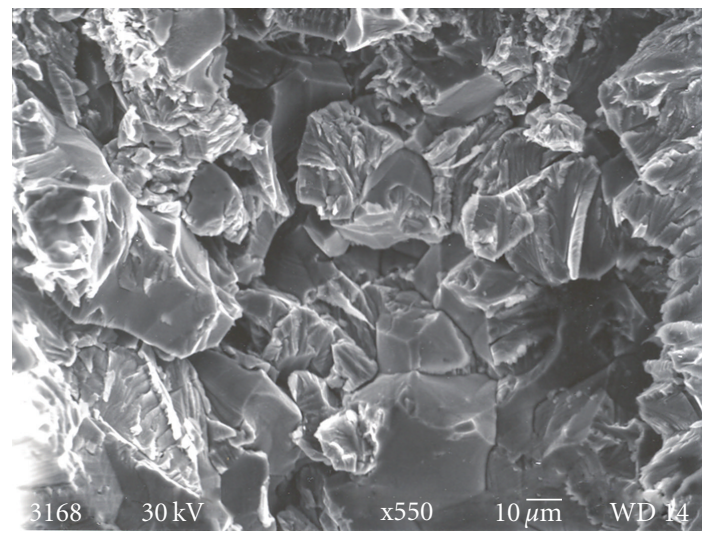

(c)

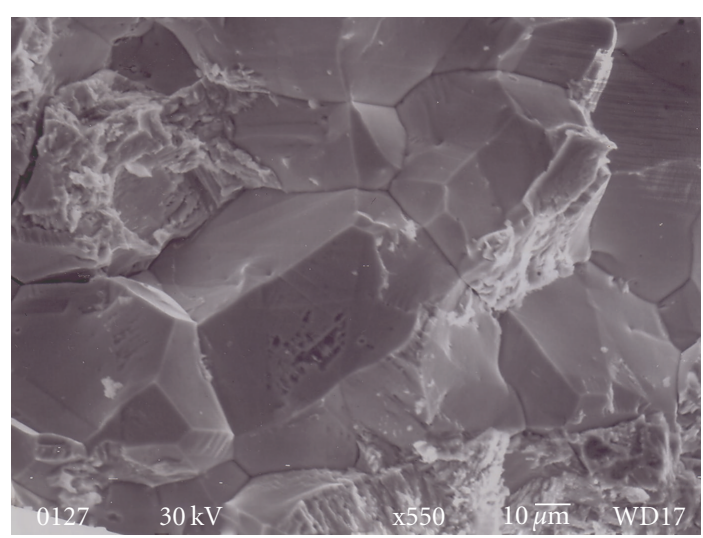

(b)

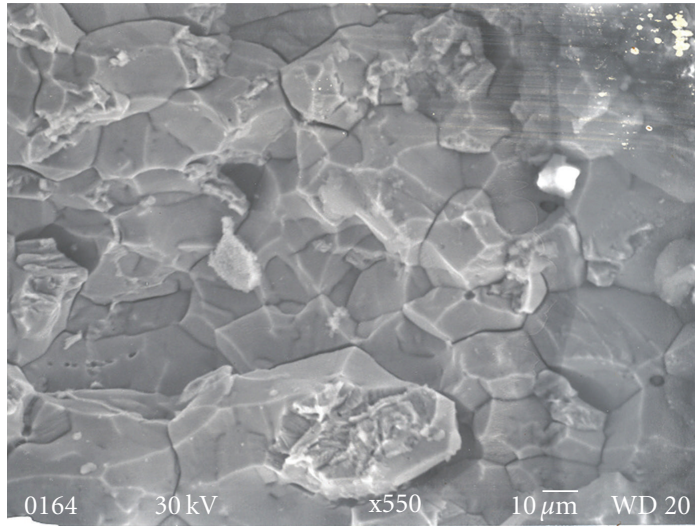

(d)

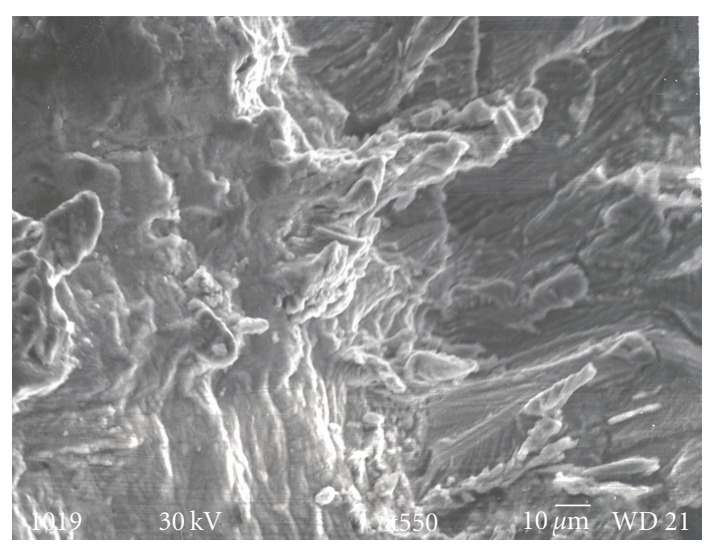

(e)

Figure 3: (a) Transgranular cracking for type 304 at $T=527 \mathrm{~K}$, (b) intergranular cracking for type 304 austenitic stainless steel at $T=403 \mathrm{~K}$ (x550), (c) transgranular cracking for type 316 austenitic stainless steel at $T=527 \mathrm{~K}$, (d) intergranular cracking for type 316 austenitic stainless steel at $T=414 \mathrm{~K}$ (x550), and (e) transgranular cracking for type 310 austenitic stainless steel at $T=414 \mathrm{~K}$ in boiling saturated $\mathrm{MgCl}_{2}$ solutions.

of martensite formation was found so that the only possible cracking mechanism will be the film-rupture mechanism [19].

Figure 3 shows the fracture surface scanning electron microscopic examination (SEM) for the steels used in the experiments. For types 304 and 316, it can be seen that there exist two fracture modes, transgranular cracking mode which occurred at test temperature above the critical test temperature corresponding to the type of steel and inter- granular cracking mode which took place at test temperatures below the critical test temperature corresponding to the type of steel. On the other hand, type 310 showed only transgranular cracking mode at all test temperatures.

\section{Effect of Applied Stress}

Figure 4 depicts the relationships between applied stress $(\sigma)$ and logarithm of time to failure $\left(t_{f}\right)$ for the three stainless 


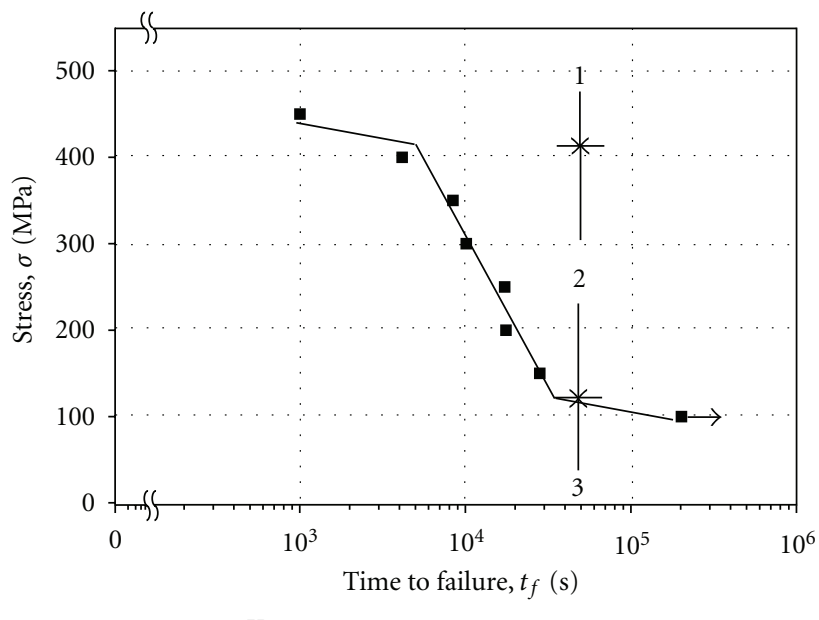

- $310-416 \mathrm{~K}$

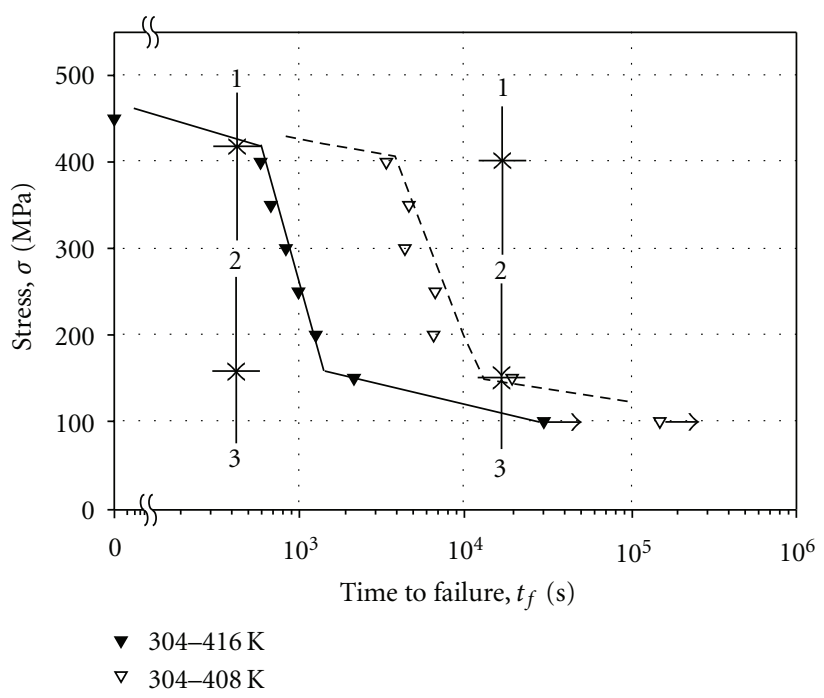

(b)

(a)

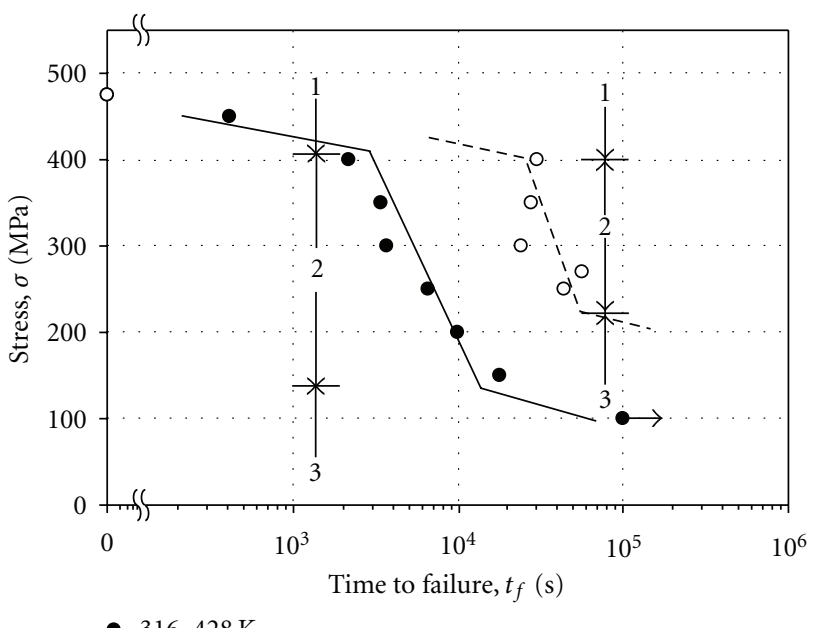

○ $316-408 \mathrm{~K}$

(c)

Figure 4: The relationship between applied stress $(\sigma)$ and logarithm of time to failure $\left(t_{f}\right)$ for type 310 , 304, and 316 steels in boiling saturated $\mathrm{MgCl}_{2}$ solutions.

steels at three test temperatures used. All relationships can be clearly divided into three regions shown by Arabic numerals $1-3$ in Figure 3; region 1 is the stress-dominated region, region 2 the stress corrosion cracking-dominated region, and region 3 the corrosion-dominated region.

In region $2, t_{f}$ values for type 304 steel at $416 \mathrm{~K}$ and for type 316 steel at $428 \mathrm{~K}$ are shorter than those at $408 \mathrm{~K}$, and $t_{f}$ for type 304 steel is shorter than that for type 316 steel. In addition, the applied stress range in region 2 for type 316 steel at $408 \mathrm{~K}$ is narrower than that for type 304 steel at $408 \mathrm{~K}$; the maximum applied stress in region 2 is the same for both steels, but the minimum applied stress for type 316 steel is higher than that for type 304 steel. At higher temperatures, the applied stress range in region 2 is almost the same for three stainless steels, and the time to failure is in the order of type $304<$ type $316<$ type 310 .
In the applied stress region where the stress corrosion cracking-dominated fracture occurred, the fracture mode for type 304 and 316 steels at 416 and $428 \mathrm{~K}$ was transgranular, while that at $408 \mathrm{~K}$ was mostly intergranular, in particular at higher applied stresses (Figure 5). In other words, for type 304 and 316 steels in boiling magnesium chloride solutions, the fracture mode was transgranular at higher temperatures and intergranular at the lower temperature. The minimum applied stress to induce intergranular cracking for type 316 steel was significantly higher than that for type 304. For type 310 steel, only transgranular fracture was found as far as stress corrosion cracking occurred in any temperatures in boiling magnesium chloride solutions [10].

In general, transgranular cracking was characterized by a higher steady-state elongation rate in both stress corrosion cracking-dominated and stress-dominated regions and 


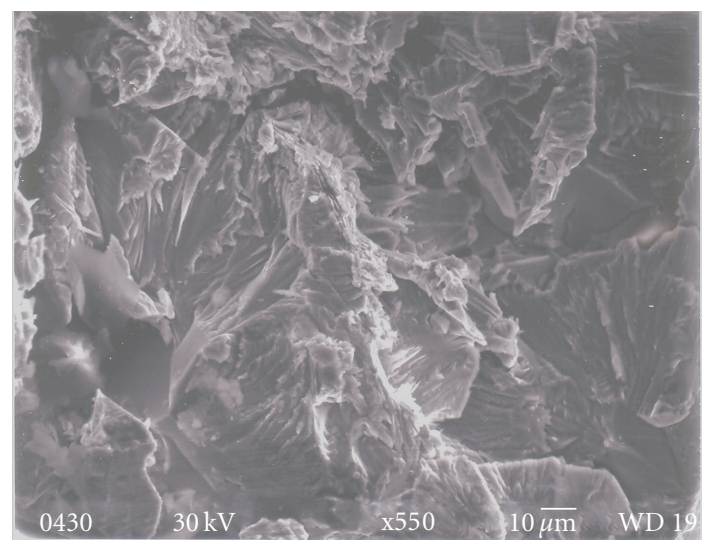

(a)

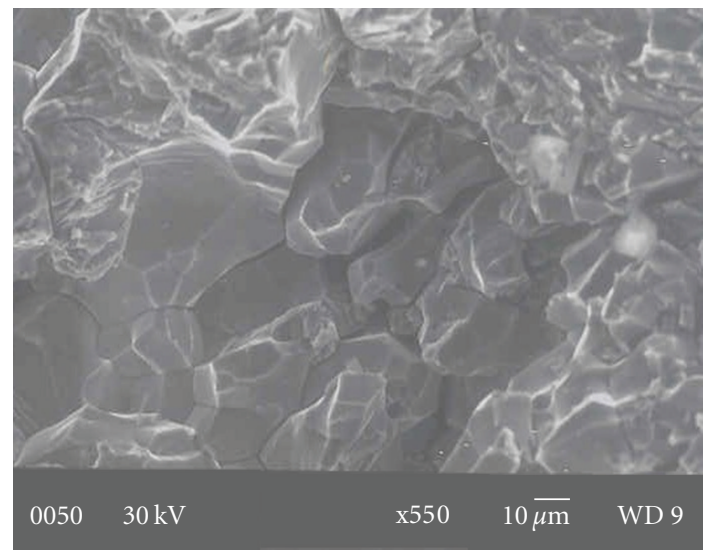

(c)

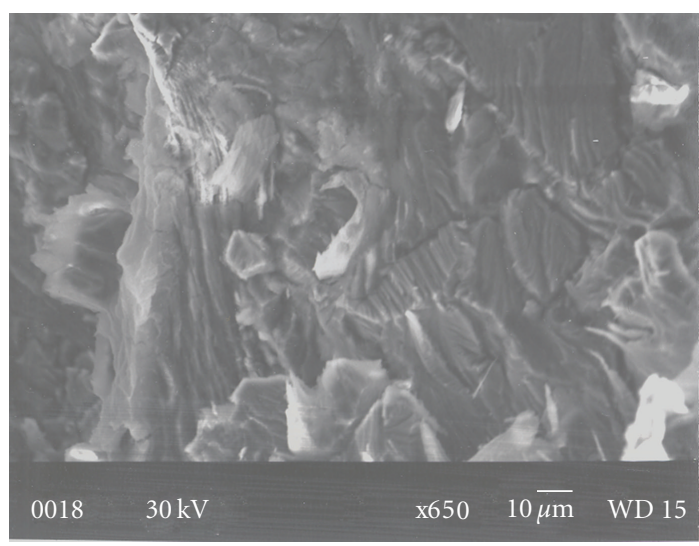

(b)

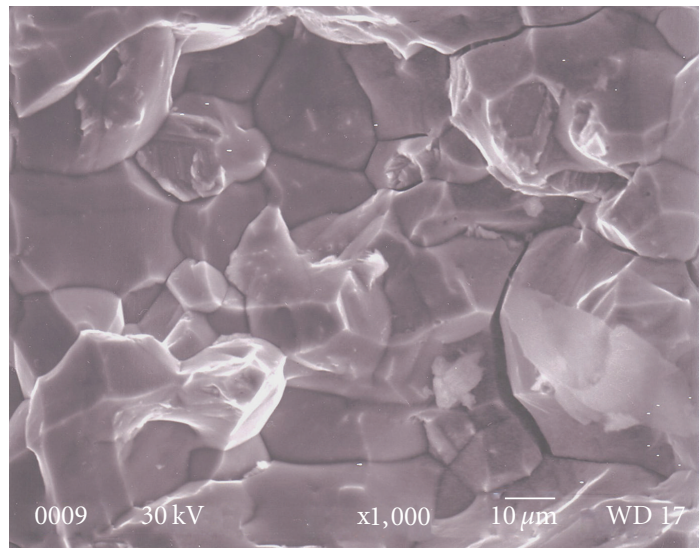

(d)

FIgURE 5: Fracture appearances for (a) type 304 at $T=416 \mathrm{~K}$ and $\sigma=300 \mathrm{MPa}$; 5550 (b) for type 310 at $T=416 \mathrm{~K}$ and $\sigma=300 \mathrm{MPa}$; 650 , (c) for type 316 at $T=408 \mathrm{~K}$ and $\sigma=300 \mathrm{MPa}$; 550 and (d) for type 316 at $T=408 \mathrm{~K}$ and $\sigma=400 \mathrm{MPa}$; 1000 in boiling saturated $\mathrm{MgCl}_{2}$ solutions.

shorter time to failure. By contrast, the failure in intergranular cracking was slow and most of the time to failure was in the steady-state elongation region indicating the small mechanical elongation until failure. Consequently, intergranular cracking for these austenitic stainless steels in the boiling magnesium chloride solution revealed more brittle nature in comparison with transgranular cracking.

Type 304 steel is a metastable austenite and is highly susceptible to martensite formation [14]. Type 316 steel is also a metastable austenite and is moderately susceptible to martensite formation [18]. On the other hand, type 310 steel is known to be less susceptible to martensite formation [17]. For metastable austenitic stainless steels like type 304 and 316 steels, the strain-induced formation of martensite tends to take place along grain boundaries and particularly is facilitated by hydrogen entry $[16,20]$. The presence of martensite is known to induce hydrogen embrittlement (HE) because of very high hydrogen diffusivity coefficient and very small hydrogen content compared to those of the austenite [18]. Thus, martensite formed at grain boundaries is apt to be responsible for $\mathrm{HE}$ of intergranular mode, and type
304 and 316 steels have higher susceptibility to martensiteinduced HE of intergranular mode, but type 310 has little susceptibility to martensite-induced $\mathrm{HE}$ of intergranular mode.

On the other hand, transgranular cracking is caused by propagation of cracks nucleated at slip steps and is not related to martensite formed at grain boundaries. Thus stress corrosion cracking in the narrow sense of the word (SCC) includes such transgranular cracking.

Type 304 and 316 steels suffered intergranular cracking at a lower temperature $(408 \mathrm{~K})$ and transgranular cracking at higher temperatures ( $428 \mathrm{~K}$ for type 316 and $416 \mathrm{~K}$ for type 304$)$. In determining the cracking mode, a competition between dissolution of material at slip steps inducing SCC and hydrogen entry inducing $\mathrm{HE}$ is the decisive factor as well as the formation of martensite. The hydrogen entry is determined by the difference between hydrogen absorption and hydrogen escape. Transgranular SCC for type 304 and 316 steels was caused by propagation of cracks nucleated at slip steps, not at martensite at grain boundaries [20]. Therefore, the cracking mode would be determined by 
the competition between the dissolution rate at slip steps and the hydrogen entry rate at grain boundaries with martensite. As test temperature increases, the dissolution rate increases. On the other hand, both hydrogen absorption rate and hydrogen escape rate increase with increasing test temperature, whereas the amount of hydrogen entry decreases, because the hydrogen escape rate becomes superior to the hydrogen entry rate with increasing temperature. This means that the amount of hydrogen entry decreases with increasing test temperature [21]. In addition, it is considered that the amount of martensite decreases with increasing test temperature, which suggests that the hydrogen entry rate decreases with increasing test temperature [22]. Thus, the dissolution rate becomes higher than the hydrogen entry rate at higher temperatures. This will result in transgranular SCC at higher temperatures.

On the other hand, it is known that the amount of martensite increases with strain or applied stress [15]. At $408 \mathrm{~K}$ for type 304 and 316 steels, the fracture mode changed from a mixed transgranular and intergranular mode to a complete intergranular mode with increasing applied stress. If cracking failure at $408 \mathrm{~K}$ is caused by martensite-induced $\mathrm{HE}$, the increase in intergranular mode with increasing applied stress is in agreement with an increase in the amount of martensite with increasing applied stress. Similarly, the minimum applied stress to induce intergranular cracking for type 316 steel was significantly higher than that for type 304 steel in agreement with the fact that type 316 steel is less susceptible to stress-induced martensite formation than type 304 steel. Furthermore, type 304 steel was more susceptible to intergranular cracking in comparison with type 316 steel in agreement with the fact the 304 steel has higher susceptibility to strain-induced martensite formation in comparison with type 316 steel.

Consequently, intergranular cracking observed at the lower temperature, that is, $408 \mathrm{~K}$ for type 304 and 316 steels is due to grain boundary martensite-induced hydrogen embrittlement (HE) and transgranular cracking for type 304 and 316 steels at higher temperatures at 416 and $428 \mathrm{~K}$ and for 310 steel is ascribed to stress corrosion cracking in the narrow sense of the word (SCC).

\section{Effect of Sensitization}

Figure 6 depicts the logarithm of $t_{f}$ versus $1 / T$ for the three sensitized stainless steels (solid lines) and for the solutionannealed stainless steels (dashed lines) for comparison. For sensitized type 304, the relationship between $t_{f}$ and $1 / T$ consisted of two straight lines denoted as region-I and region-II below and above a test temperature of about $413 \mathrm{~K}$ $\left(1 / T=2.42 \times 10^{-3}\right)$. The time to failure was found to be larger for the sensitized specimens than for the solutionannealed specimens over the whole test temperature range, and in addition, the critical test temperature between regionI and region-II has shifted from $408 \mathrm{~K}\left(1 / T=2.45 \times 10^{-3}\right)$ for the solution-annealed specimen to $413 \mathrm{~K}(1 / \mathrm{T}=2.42 \times$ $10^{-3}$ ) for the sensitized one.

For type 316, although the relationship between $\log t_{f}$ and $1 / T$ for the solution-annealed specimen was composed of two regions (region-I and region-II) [10], that for the sensitized specimen showed only one region which corresponded to region-II for the solution-annealed specimens and had no region-I over the whole test temperature range as described later. In addition, it can be noted that there was approximately two orders of magnitude difference in the time to failure between the solution-annealed and sensitized specimens. On the other hand, the relationship for the sensitized type 310 showed only one region as well as that for type 316 , but the behavior for type 310 was found to correspond to region-I as described later. The $t_{f}$ for type 310 showed a small difference between the sensitized and solution-annealed specimens. It was, therefore, clearly found that sensitization provided a beneficial effect for types 304 and 316 and a slight effect for type 310 on the fracture susceptibility. The cracking modes for the sensitized steels were similar to the modes observed in the effect of test temperature experiments, for types 304 and 316 the samples exhibited transgranular cracking mode above the critical temperature and intergranular cracking mode below the critical temperature. And the transgranular cracking was dominant for all test temperatures for type 310 .

\section{A Proposal for Transgranular Hydrogen Embrittlement Mechanism}

Sensitized type 316 had higher corrosion resistance than solution-annealed type 316 and sensitized type 304. From Figure 4, it would be also predicted that the sensitized type 316 has a higher transition temperature than that of sensitized type 304 . $T_{\text {trans }}$ thus predicted would be higher than the maximum test temperature experimentally conducted, since TG-SCC was not detected over the test temperature range conducted. However, the experimental result showed that TG-HE instead of IG-HE was observed for sensitized type 316 at a higher test temperature. Therefore, we need to consider why TG-HE occurred at the higher test temperature, since only IG-HE was predicted to occur over the range of test temperature used.

The difference between TG-HE and IG-HE is where the anodic reaction takes place at grain boundaries or at slip steps. This means that at a transition test temperature $\left(T_{\text {trans }}^{\mathrm{HE}}\right)$ from IG-HE to TG-HE or vice versa, the preferential site for anodic reaction changes from slip steps to grain boundaries or vice versa. To explain this phenomenon, the change in the degree of corrosion of sensitized types 304 and 316 with test temperature must be considered. On the basis of the results experimentally obtained, one can make the following assumptions.

(1) The degree of Cr depletion is smaller for sensitized type 316 than for the sensitized type 304 under the identical heat treatment condition; the fracture susceptibility based on $\mathrm{Cr}$ depletion for sensitized type 304 is higher than that for sensitized type 316.

(2) The inhibiting effect of chloride ions at Cr depletion becomes larger with increasing the degree of $\mathrm{Cr}$ depletion; that is, the inhibiting effect of chloride ions 


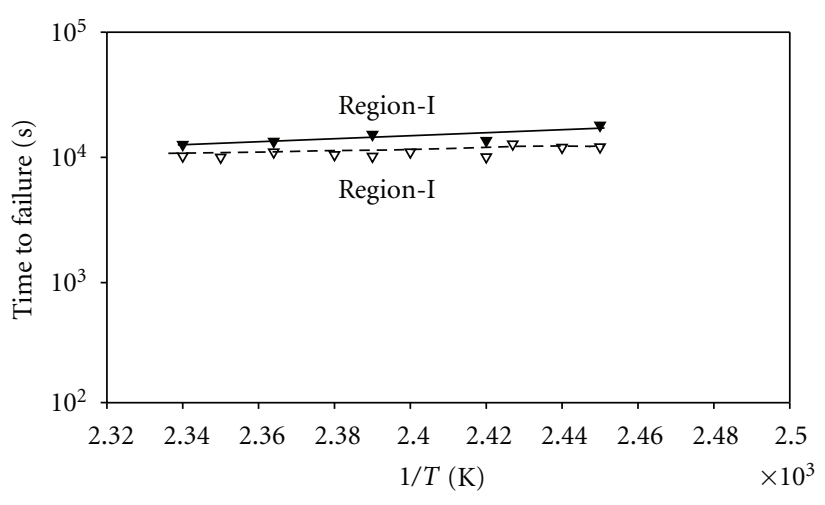

- Sensitized type 310

$\nabla$ Solution annealed type 310

(a)

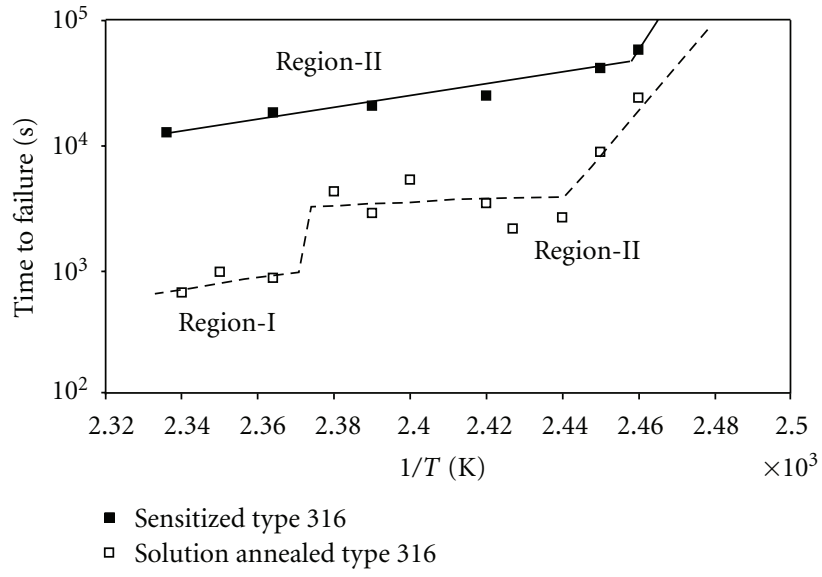

(b)

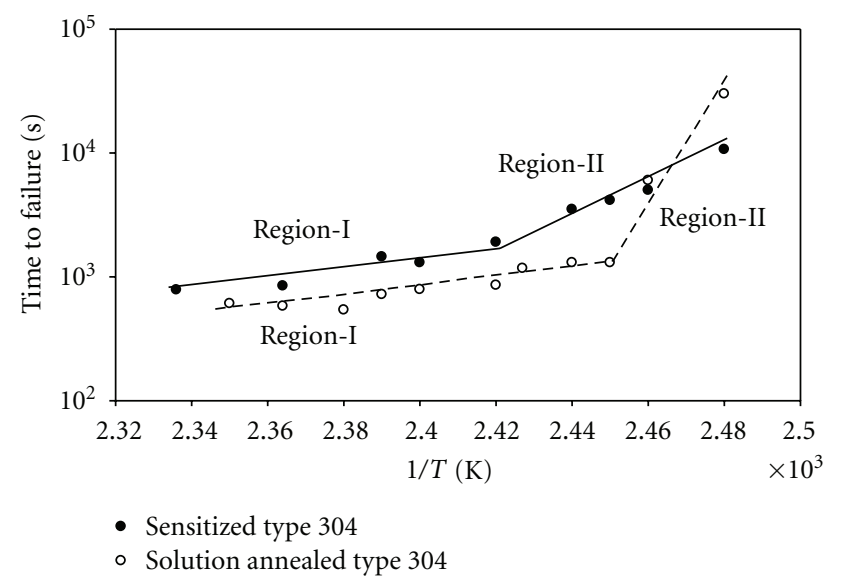

(c)

FIGURE 6: The relationship between reciprocal of test temperature $(1 / T)$ and logarithm of time to failure $\left(t_{f}\right)$ for sensitized type 310,304 and 316 steels in boiling saturated $\mathrm{MgCl}_{2}$ solutions.

at $\mathrm{Cr}$ depletion for sensitized type 304 is higher than that for sensitized type 316 .

(3) However, the degree of corrosion for the sensitized type 304 is larger than that for the sensitized 316 even by the inhibiting effect of chloride ions; that is, corrosive dissolution of sensitized type 304 is larger than that of sensitized type 316 .

With respect to sensitized type 316 with higher corrosion resistance, the crack nucleation and propagation could not take place at slip steps or grain boundaries with anodic reaction over the range of test temperature used, whereas the fresh surface of slip steps may be able to act as the site for the cathodic hydrogen evolution. Under such a condition, as test temperature increases, anodic reaction would be enhanced more at grain boundaries than at slip steps due to the existence of $\mathrm{Cr}$ depleted zones, and the preferential site for anodic reaction would change from slip steps to grain boundaries. This would be the reason why the fracture mode changes from IG-HE to TG-HE.

On the basis of the considerations described in the previous sections, a mechanism for TG-HE can be proposed with a new aspect under the assumptions described below, where the IG-HE mechanism has already been reported in the previous work [14].

(1) The $\alpha^{\prime}$-martensite serves as an obstacle for dislocation movement on the slip plane as well as grain boundary sliding (GBS) for IG-HE.

(2) The $\alpha^{\prime}$-martensite does not self-destruct, even if it grows with enough thickness.

(3) The $\alpha^{\prime}$-martensite and the $\mathrm{Cr}$ depleted zone can serve as a preferential site for dissolution (with film formation) or hydrogen permeation. If the phenomenon at grain boundaries is considered, hydrogen permeation at grain boundaries will not induce TG-HE.

(4) The diffusing hydrogen $\left(H_{\text {dif }}\right)$ leads to the enhancement of dislocation movement at slip plane as well as GBS; that is, HELP.

As soon as a load is applied to the specimens, a crack nucleation would take place at slip steps with the stress- and hydrogen-induced martensite. During the crack nucleation period, $\alpha^{\prime}$-martensite grows and simultaneously $H_{\text {dif }}$ leads 


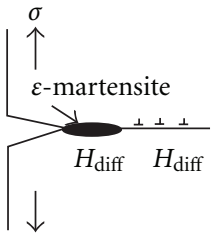

(a)

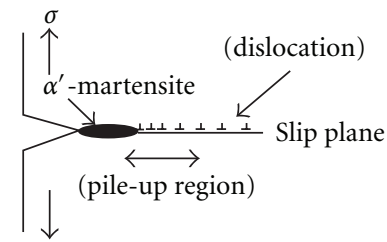

(b)

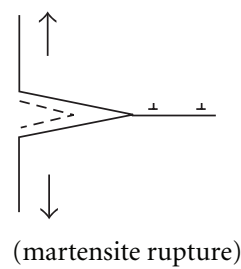

(c)

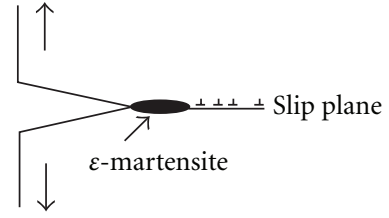

(d)

FiguRE 7: Schematic representation of a transgranular hydrogen embrittlement caused by the formation of $\alpha^{\prime}$-martensite and dislocation pile-up.

to HELP. An additional local stress $\left(\sigma_{\text {add }}\right)$ would be generated by an interaction between $\alpha^{\prime}$-martensite and dislocation movement by HELP in addition to a local stress caused by applied stress $\left(\sigma_{\text {app }}\right)$. Therefore, a net local stress $\left(\sigma_{\text {tip }}\right)$ consists of $\sigma_{\text {app }}$ and $\sigma_{\text {add }}$

$$
\sigma_{\text {tip }}=\sigma_{\text {app }}+\sigma_{\text {add }}
$$

Under a constant applied stress condition, $\sigma_{\text {app }}$ is constant, and $\sigma_{\text {add }}$ increases with time. When $\sigma_{\text {tip }}$ reaches a critical fracture stress $\left(\sigma_{F}\right), \alpha^{\prime}$-martensite rupture takes place:

$$
\sigma_{F}=\sigma_{\text {app }}+\sigma_{\text {add }}^{\mathrm{Max}},
$$

where $\sigma_{\text {add }}^{\mathrm{Max}}$ is the maximum additional local stress for $\sigma_{\text {tip }}$ to reach $\sigma_{F}$ and $\sigma_{F}$ is assumed to be constant independent of applied stress and test temperature but depends upon the materials. Just after $\alpha^{\prime}$-martensite rupture, $\sigma_{\text {tip }}$ drops to $\sigma_{\text {app }}$ (= constant under a constant applied stress condition) and then increases with the increase in $\sigma_{\text {add }}$ during $\alpha^{\prime}$-martensite growth up to $\sigma_{F}$, that is, $\sigma_{\text {app }} \leqq \sigma_{\text {tip }} \leqq \sigma_{F}$ or $0 \leqq \sigma_{\text {add }} \leqq \sigma_{\text {add }}^{\mathrm{Max}}$. After the crack nucleation period, the crack propagation period proceeds with the cyclic formation-rupture event of $\alpha^{\prime}$-martensite. Figure 7 shows a schematic representation of the cyclic formation-rupture event of $\alpha^{\prime}$-martensite along with the above considerations.

Under a constant applied stress condition, an increase rate in $\sigma_{\text {tip }}$ is provided from $(1)$

$$
\frac{d \sigma_{\mathrm{tip}}}{d t}=\frac{d \sigma_{\mathrm{add}}}{d t}
$$

where $d \sigma_{\mathrm{app}} / d t$ becomes zero as $\sigma=$ constant. The number of the pile-up dislocation at crack tips $\left(n_{\text {tip }}\right)$ is composed of $n_{\text {app }}$ caused by $\sigma_{\text {app }}$ and $n_{\text {add }}$ by $\sigma_{\text {add }}$ during $\alpha^{\prime}$-martensite formation

$$
n_{\text {tip }}=n_{\text {app }}+n_{\text {add }}
$$

The $n_{\text {app }}$ is constant $\left(d n_{\text {app }} / d t=0\right)$ under the constant applied stress condition and hence,

$$
\left.\frac{d n_{\text {tip }}}{d t}=\frac{d n_{\mathrm{add}}}{d t} \quad \text { (during } \alpha^{\prime} \text {-martensite formation }\right) .
$$

According to Tetelman and McEvily [23], a plastic displacement by dislocation movement is connected with an elastic shear displacement as follows:

$$
n_{\text {tip }} \cdot b=L_{\text {tip }} \frac{\left(\tau-\tau_{i}\right)}{G},
$$

where $b$ is the Burgers vector, $L_{\text {tip }}$ is the length of the pile-up dislocation, $\tau$ is the shear stress $(\sigma=2 \tau), \tau_{i}$ is the friction stress, and $G$ is the shear modulus. In addition, $L_{\text {tip }}$ is also composed of $L_{\text {app }}$ caused by $\sigma_{\text {app }}$ and $L_{\text {add }}$ formed during $\alpha^{\prime}$ martensite formation,

$$
L_{\text {tip }}=L_{\text {app }}+L_{\text {add }}
$$

where $L_{\text {app }}$ is constant, $d L_{\mathrm{app}} / d t=0$ as well as $n_{\mathrm{app}}$, and then

$$
\frac{d L_{\mathrm{tip}}}{d t}=\frac{d L_{\mathrm{add}}}{d t} \quad \text { (during } \alpha^{\prime} \text {-martensite formation). }
$$

Furthermore, a concentrated tensile stress, corresponding to $\sigma_{\text {tip }}$, is expressed as

$$
\sigma_{\text {tip }} \propto\left(\tau-\tau_{i}\right)\left(\frac{L_{\text {tip }}}{r}\right)^{1 / 2} F(\varphi) \quad\left(b \ll r \ll L_{\text {tip }}\right),
$$

where $r$ is the length from the tip of a crack to the tip of the pile up which corresponds to the $\alpha^{\prime}$-martensite thickness at crack tips, and $F(\varphi)$ is a function of $\varphi$, that is, an angle between planes in adjacent grains.

On the other hand, a hydrogen permeation current $\left(j_{\text {perm }}\right)$ would be proportional to a hydrogen evolution current density $\left(j_{c}\right)$ as the cathodic reaction. Furthermore, $j_{\text {perm }}$ consists of $j_{\text {dif }}$ associated with the diffusing hydrogen leading to HELP and $j_{\text {martensite }}$ contributing to the formation of $\alpha^{\prime}$ martensite,

$$
j_{\text {perm }}=j_{\text {martensite }}+j_{\text {dif }}
$$

As only $j_{\text {dif }}$ is associated with $d n_{\text {dis }} / d t$, the following relation is obtained

$$
\frac{j_{\mathrm{dif}}}{z F} \propto \frac{d n_{\mathrm{dis}}}{d t}
$$

Equation (11) shows that as $j_{\text {dif }}$ increases, $d n_{\text {dis }} / d t$ increases proportionally. From (7), (9), and (11), the following relation is given

$$
\frac{d n_{\mathrm{dis}}}{d t} \propto \frac{d L_{\mathrm{dis}}}{d t}
$$

Furthermore, from (9) an increasing rate of $\sigma_{\text {tip }}$ under each constant applied stress condition is expressed as

$$
\frac{d \sigma_{\text {tip }}}{d t} \propto\left(\tau-\tau_{i}\right)\left(\frac{L_{\text {tip }}}{r}\right)^{-1 / 2} \frac{d L_{\text {tip }}}{d t} .
$$




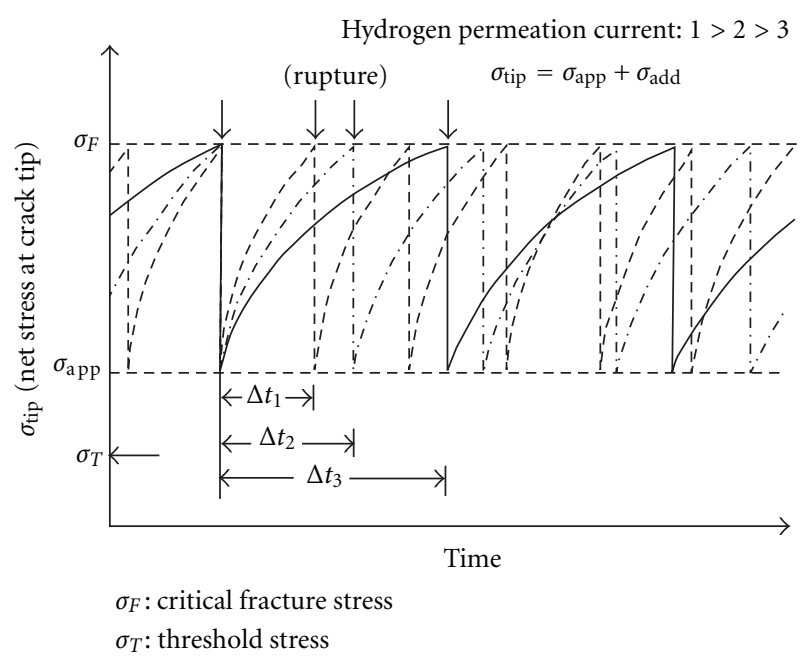

FIgURE 8: Schematic representation of time dependence of the net local stress $\left(\sigma_{\text {tip }}\right)$ during the film rupture-formation events at various hydrogen permeation currents under a constant applied stress condition, where $\sigma_{T}$ is the threshold stress below which no HE takes place and $\sigma_{F}$ is the critical fracture stress at or above which the failure of $\alpha^{\prime}$-martensite occurs.

From (11), (12) and (13), (14) is provided as

$$
\frac{d \sigma_{\mathrm{tip}}}{d t} \propto\left(\tau-\tau_{i}\right)\left(\frac{L_{\mathrm{tip}}}{r}\right)^{-1 / 2} \frac{j_{\mathrm{dif}}}{z F},
$$

where $L_{\text {tip }}$ and $r$ are the values at $\sigma_{F}$, which are assumed to be constant. Finally, it is recognized that $d \sigma_{\text {tip }} / d t$ is dependent on $\tau$ and $j_{\text {dif. }}$. Thus, the TG-HE mechanism of the sensitized type 316 is considered to take place by the cyclic $\alpha^{\prime}$-martensite formation-rupture event with a help of HELP caused by the diffusing hydrogen.

Figure 8 shows the schematic representation of the time variation of $\sigma_{\text {tip }}$ at various permeation current densities under constant applied stress conditions. When $\sigma_{\text {tip }}$ reaches $\sigma_{F}$, the rupture of $\alpha^{\prime}$-martensite takes place. Then $\sigma_{\text {tip }}$ returns to $\sigma_{\text {app }}$ and simultaneously begins to increase with increasing $\sigma_{\text {add }}$ and this process is repeated.

As the permeation current density increases, the frequency of the formation-rupture event of $\alpha^{\prime}$-martensite increases with a consequent increase in the TG-HE susceptibility. Correspondingly, Figure 9 shows the schematic representation of the time variation of a net elongation $\left(l_{n}\right)$, which corresponds to that of $\sigma_{\text {tip }}$ in Figure 8, where $l_{n}$ is composed of $l_{\text {app }}$ caused by applied stress and $l_{\text {add }}$ caused during the process of $\alpha^{\prime}$-martensite formation; $l_{n}=l_{\text {app }}+$ $l_{\text {add }}$. An average elongation rate becomes the steady-state elongation rate, $l_{s s}$, although we could not observe the step by step on the elongation increase such as that in Figure 7 for TG-HE of the austenitic stainless steels.

\section{Conclusions}

(i) Using a constant load method, the effect of test temperature on stress corrosion cracking of austenitic stainless steels can be evaluated. There was two re-

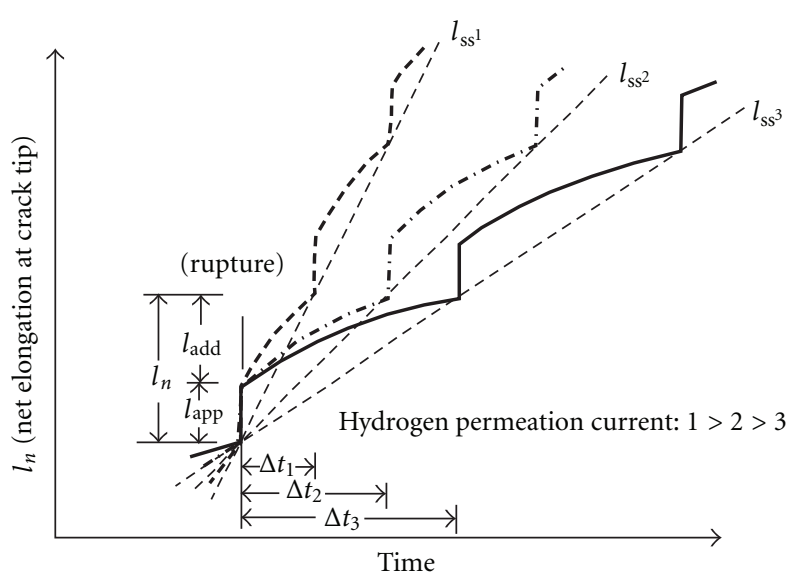

FIGURE 9: Schematic representation of time dependence of the net elongation $\left(l_{n}\right)$ during the film rupture-formation events at various hydrogen permeation currents under a constant applied stress condition, which corresponds to that in Figure 7.

gions obtained, one for SCC-dominated failure and the other for hydrogen embrittlement dominated failure.

(ii) The cracking mechanism for type 304 was transgranular between test temperatures of $413 \mathrm{~K}$ and $428 \mathrm{~K}$. The cracking mode for type 304 changed to intergranular at test temperatures between $412 \mathrm{~K}$ and $403 \mathrm{~K}$. The cracking mechanism for type 316 was transgranular between test temperatures of $424 \mathrm{~K}$ and $428 \mathrm{~K}$. The cracking mechanism for type 316 was a mixture of transgranular and intergranular cracking for test temperatures between $424 \mathrm{~K}$ and $408 \mathrm{~K}$. The cracking mechanism for type 310 was transgranular at test temperatures higher than $408 \mathrm{~K}$ and no intergranular cracking behavior was observed.

(iii) The reason for the intergranular cracking mechanism for types 304 and 316 might be the formation of martensite at the grain boundary where as for type 310 no martensite transformation existed which contributed to the cracking mechanism uniformity. This behavior for types 304 and 316 requires further investigation.

(iv) The fracture susceptibility (SCC and HE) became lower for the sensitized austenitic stainless steels than for the solution-annealed ones. This was estimated to be caused by the inhibiting effect of chloride ions on anodic reaction (dissolution).

(v) Sensitized type 304 had two different cracking modes (TG-SCC and IG-HE) as well as for the solutionannealed one. However, the critical test temperature from IG-HE to TG-SCC shifted to a higher test temperature for the sensitized type 304 than for the solution-annealed one. On the other hand, the fracture behavior of type 310 had the same with and without sensitizing temperature treatment. 
(vi) An HE mechanism with a new aspect was proposed in terms of martensite transformation, hydrogen entry site, sensitization, the role of diffusing hydrogen, dislocation movement (or grain boundary sliding) and so on.

\section{Acknowledgment}

The authors would like to acknowledge the funding provided by Kuwait University under Grant no. EM05/02.

\section{References}

[1] T. P. Hoar and J. M. West, "Mechano-chemical anodic dissolution of austenitic stainless steel in hot chloride solution," Proceeding of the Royal Society A, vol. 268, pp. 304-315, 1962.

[2] T. P. Hoar and J. C. Scully, "Mechanochemical anodic dissolution of austenitic stainless steel in hot chloride solution at controlled electrode potential," Journal of the Electrochemical Society, vol. 111, no. 3, pp. 348-352, 1964.

[3] R. Nishimura and Y. Maeda, "Stress corrosion cracking of type 304 austenitic stainless steel in sulphuric acid solution including sodium chloride and chromate," Corrosion Science, vol. 46, no. 2, pp. 343-360, 2004.

[4] T. Nakayama and M. Takano, "Application of a slip dissolution-repassivation model for stress corrosion cracking of AISI 304 stainless steel in a boiling $42 \% \mathrm{MgCl}_{2}$ solution," Corrosion, vol. 42, no. 1, pp. 10-15, 1986.

[5] M. B. Whiteman and A. R. Troiano, "Troiano, hydrogen embrittlement of austenitic stainless steel," Corrosion, vol. 21, pp. 53-56, 1965.

[6] M. L. Holzworth, "Hydrogen embrittlement of type 304L stainless steel," Corrosion, vol. 25, pp. 107-115, 1969.

[7] P. R. Rhodes, "Mechanism of chloride stress corrosion cracking of austenitic stainless steels," Corrosion, vol. 25, no. 11, pp. 462-472, 1969.

[8] R. Nishimura and H. Sulaiman, "Stress corrosion cracking of sensitized type 316 austenitic stainless steel in pure sulfuric acid solution," in Corrosion Control for Low Cost Reliability, p. 4325, 1993.

[9] R. Nishimura and Y. Maeda, "Metal dissolution and maximum stress during SCC process of ferritic (type 430) and austenitic (type 304 and type 316) stainless steels in acidic chloride solutions under constant applied stress," Corrosion Science, vol. 46, no. 3, pp. 755-768, 2004.

[10] O. M. Alyousif and R. Nishimura, "The effect of test temperature on SCC behavior of austenitic stainless steels in boiling saturated magnesium chloride solution," Corrosion Science, vol. 48, no. 12, pp. 4283-4293, 2006.

[11] O. M. Alyousif and R. Nishimura, "The stress corrosion cracking behavior of austenitic stainless steels in boiling magnesium chloride solutions," Corrosion Science, vol. 49, no. 7, pp. 3040-3051, 2007.

[12] O. M. Alyousif and R. Nishimura, "Stress corrosion cracking and hydrogen embrittlement of sensitized austenitic stainless steels in boiling saturated magnesium chloride solutions," Corrosion Science, vol. 50, no. 8, pp. 2353-2359, 2008.

[13] O. M. Alyousif and R. Nishimura, "On the stress corrosion cracking and hydrogen embrittlement of sensitized austenitic stainless steels in boiling saturated magnesium chloride solutions: effect of applied stress," Corrosion Science, vol. 50, no. 10, pp. 2919-2926, 2008.
[14] R. Nishimura and O. M. Alyousif, "A new aspect on intergranular hydrogen embrittlement mechanism of solution annealed types 304, 316 and 310 austenitic stainless steels," Corrosion Science, vol. 51, no. 9, pp. 1894-1900, 2009.

[15] D. Eliezer, D. G. Chakrapani, C. J. Altstetter, and E. N. Pugh, "The influence of austenite stability on the hydrogen embrittlement and stress- corrosion cracking of stainless steel," Metallurgical Transactions A, vol. 10, no. 7, pp. 935-941, 1979.

[16] H. Hanninen and T. Hakarainen, "On the effects of alpha prime martensite in hydrogen embrittlement of a cathodically charged alsl type 304 austenitic stainless steel," Corrosion, vol. 36, no. 1, pp. 47-51, 1980.

[17] S. S. Birley and D. Tromans, "Stress corrosion cracing of 304 austenitic steel and the martensite transformation," Corrosion, vol. 27, pp. 63-71, 1971.

[18] X. Sun, J. Xu, and Y. Li, "Hydrogen permeation behavior in metastable austenitic stainless steels 321 and 304," Acta Metallurgica, vol. 37, no. 8, pp. 2171-2176, 1989.

[19] T.-P. Perng and C. J. Altstetter, "Effects of deformation on hydrogen permeation in austenitic stainless steels," Acta Metallurgica, vol. 34, no. 9, pp. 1771-1781, 1986.

[20] R. Nishimura, "SCC failure prediction of austenitic stainless steels in acid solutions. Effect of $\mathrm{pH}$, anion species, and concentration," Corrosion, vol. 46, no. 4, pp. 311-318, 1990.

[21] J. K. Tien, "Diffusion and the dislocation sweeping mechanism," in Effect of Hydrogen on Behavior of Materials, A. W. Thompson and I. M. Bernstein, Eds., p. 309, AIME, 1975.

[22] R. E. Reed-Hill, Physical Metallurgy Principles, Brooks/Cole Engineering Division, Monterey, Calif, USA, 2nd edition, 1973.

[23] A. S. Tetelman and A. J. McEvily Jr., Fracture of Structual Materials, John Wiley \& Sons, New York, NY, USA, 1967. 

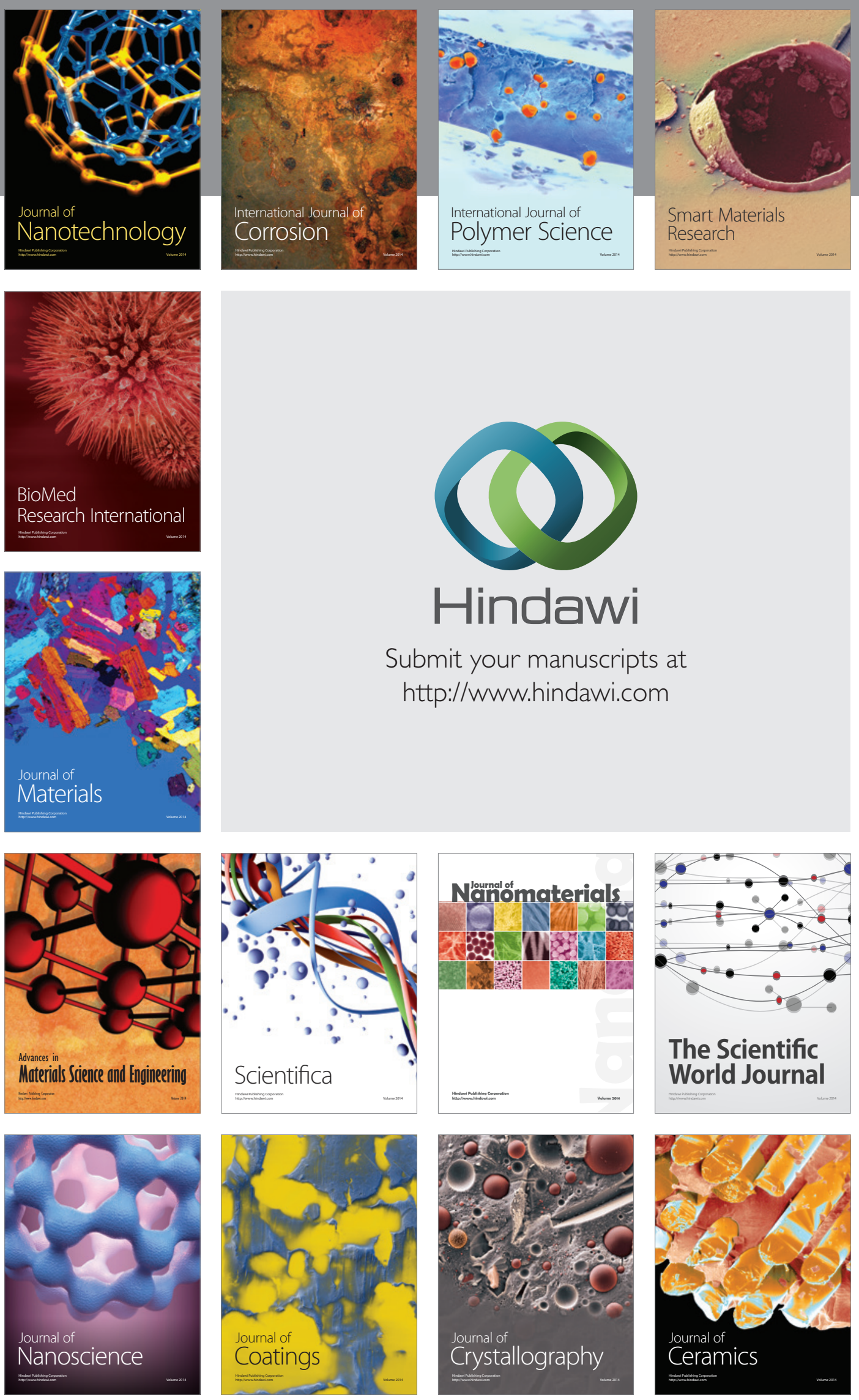

The Scientific World Journal

Submit your manuscripts at

http://www.hindawi.com

\section{World Journal}

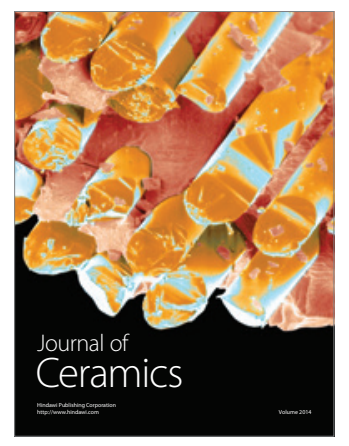

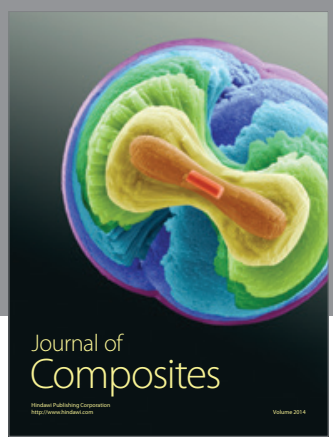
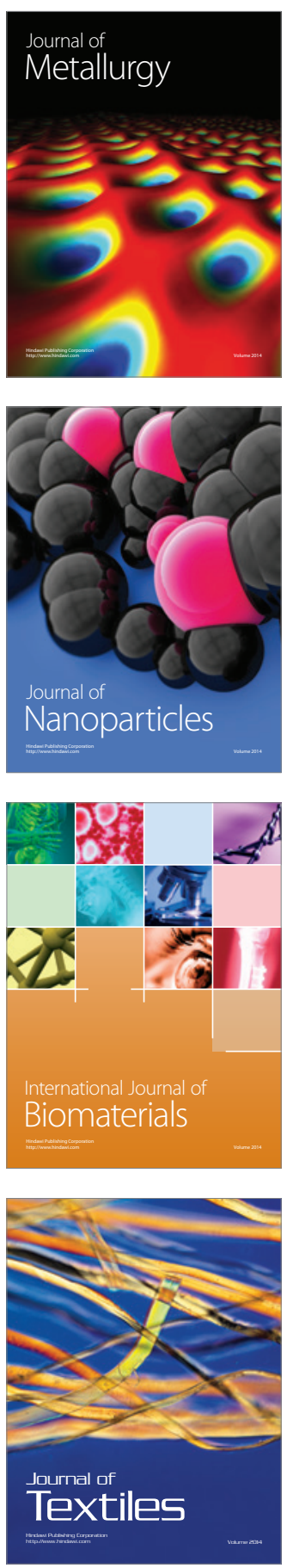